\title{
Investigating the factors affecting University students' e-commerce intention towards: a case study of Jordanian universities
}

\author{
Mohammad Mahmoud Alzubi \\ Mohammed Abdullah Alkhawlani \\ Yousef Abu Baker El-Ebiary \\ Al-Madinah International University \\ Shah Alam, Malaysia
}

\begin{abstract}
Key Words
E-Commerce, Culture, Unified Theory of Acceptance and Use of Technology (UTAUT),
\end{abstract}

\begin{abstract}
This study investigates the factors that significantly affect the acceptance e-commerce in Jordan. These factors were Culture factor and Unified Theory of Acceptance and Use of Technology (UTAUT) Characteristics. This study adopted the deductive approach to reach its objectives. It presents a theoretical framework for the construction of hypotheses. The hypotheses were tested to obtain the findings that may be generalized afterwards. 154 students from different universities in Jordan participated in this study. After reviewing several related studies, the Likert five- point scale questionnaire was constructed for gathering the required data, which were then analyzed using the SPSS software.
\end{abstract}

Corresponding author: Mohammad Mahmoud Alzubi

Email address for corresponding author: mohammad.mahmoud@mediu.edu

First submission received: 4th April 2017

Revised submission received: 11th May 2017

Accepted: 5th June 2017

\section{Introduction}

The problem of scarce e-commerce in Arab countries is not widely known in Western countries. Therefore, the paper gives quite a new insight into it. The problem may induce further discussions and research on the problem, especially what should be done to make e-commerce more popular in Arab countries. Thus, the paper may be considered as an introductory one. There has been a dramatic increase in the application of Web services and E-Commerce. Meanwhile, the once popular 'dot com era' is slowly declining (Chaffey 2007). Kalakota and Whinston (1997) describe Ecommerce as the purchase and sale of information, products and services using computer networks. Thus, according to this definition, online shopping can be classified as E-Commerce.

There has been a steady growth of online shopping. It was estimated that in USA alone, online purchasing was worth $\$ 217$ billion in 2007 (Johnson, et al., 2002). Meanwhile, Nielsen (2010) reported that in developing countries including Korea and China, almost all of the Internet users $(95 \%)$ intended to engage in online shopping. Somehow, Arab countries have less than impressive ecommerce development in comparison to their other developing counterparts. As noted by Nielsen (2010), almost half (48\%) of the Internet users in Arab countries never did online shopping, making these countries the slowest adopter of online shopping.

In the context of Jordan, the Jordanian the Chamber of Commerce noted that the development of e-commerce is still in its infancy (Abbad, et al., 2011; Hasan, L., Morris, A., \& Probets, S. 2013; Yaseen, H., Dingley, K., \& Adams, C. 2015). Nonetheless, many movements by business owners or companies as well as the government could potentially increase the expansion of ecommerce. These include the establishment of e-government websites even though most of these 
websites are far from perfect (Al-Soud \& Nakata, 2010). In other words, the government of Jordan is seriously supporting the development of e-commerce.

\section{Problem Statement}

As high technology and internet are available today, the Arabic websites should indeed be promoted. Such move is crucial considering that using these Arabic websites based on Arab countries, the Arab customers can be served faster aside from reducing transaction cost and delivery problems (Pons, et al., 2003). Additionally, there are various factors that are found to contribute to the slow development of e-commerce in Arab countries (Jordan included) and the hesitancy of consumers to engage online shopping and these factors include risk, trust, quality of websites, and security (Nusair, 2011; Faqih, 2011). Furthermore, the factors of culture and technology have been highlighted in a lot of research on online transactions and e-commerce (Ruiz Mafé et al., 2013; Lacka, E., Chan, H. K., \& Yip, N., 2014)

Most e-commerce was developed within the western culture and in fact, this is where a majority of users were gathered. Thus, it can be said that E-commerce is Western influenced. In relation to this, Morris\& Probets . (2013) mentioned the existence of numerous websites of ecommerce with design attuned to western cultures. The western countries embrace different cultures in comparison to those embraced in Arab countries including Jordan. In other words, what is tolerable in the one country might be unacceptable in others. Thus, owing to differences in cultures, the adoption of e-commerce websites can be impacted. It is therefore important to take into account the cultural values of a country when developing e-commerce.

\section{Theoretical Background}

The Unified Theory of Acceptance and Use of Technology (UTAUT) Model is explained in this part so that the determiners of user acceptance of e-commerce can be sufficiently understood. Formulated by Venkatesh et al. (2003), the Unified Theory of Acceptance and Use of Technology (UTAUT) Model entails the merged past studies associated with technology acceptance model (TAM). In particular, the establishment of UTAUT was grounded on the constructs from eight models that past studies on IS usage behaviour had employed and from literature review. Using UTAUT allows researcher to explain user intentions to utilize an Information system (IS) and his forthcoming usage behavior. The theory highlights four (4) key constructs that are direct determinants of usage intention and behaviour of user: performance expectancy, effort expectancy, social influence, and facilitating conditions. Meanwhile, the mediators that affect these determinants include age, gender, experience and voluntariness of use (Venkatesh et al., 2003). Figure 1 shows the UTAUT.

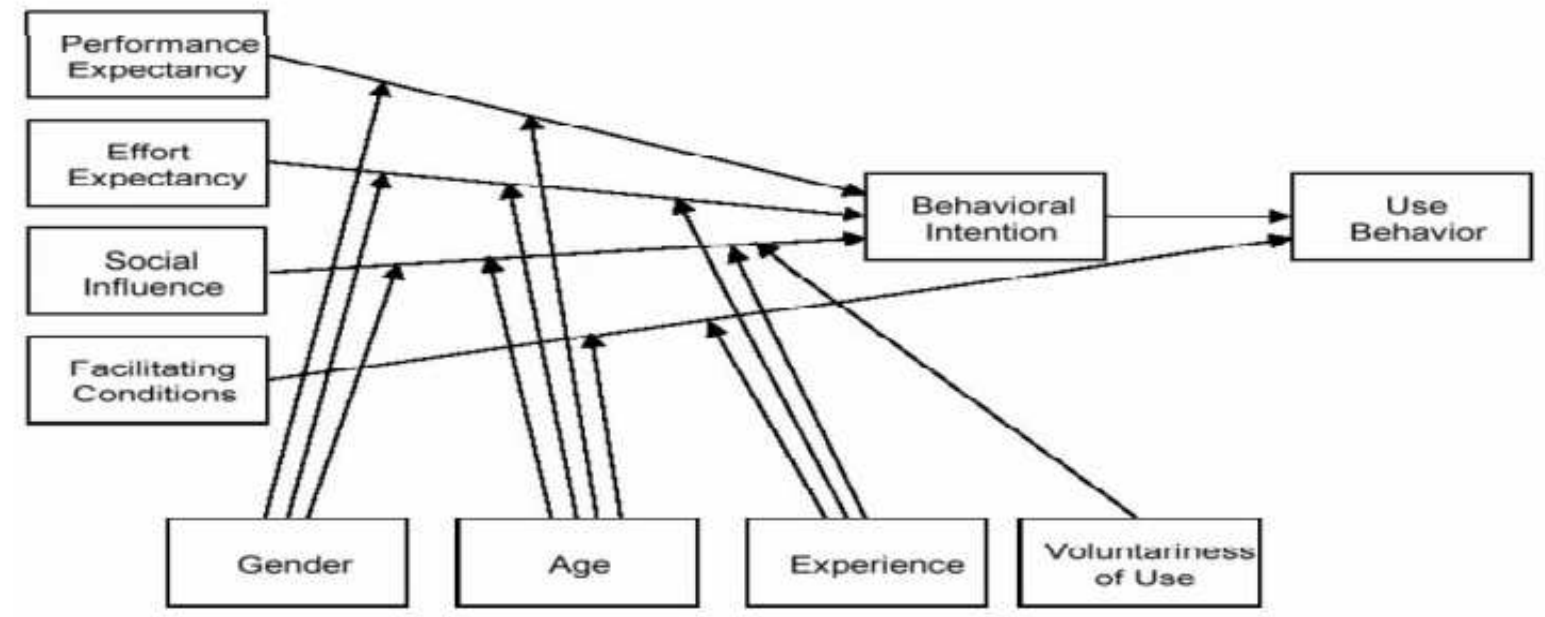

Fig. 1: Unified Theory of Acceptance and Use of Technology (UTAUT) Model Source: (Venkatesh et al., 2003) 


\section{Cultural Factor}

Culture is a notion that can facilitate the comprehension of the issues relating to human diversity discussed expansively at current time. Culture is perceivable as multicultural societies marketing, or, scholars in the domain of business view culture as national culture that includes lively process that influences numerous behavior types particularly those associated with buying and consumption (Chang \& Chuang, 2005). Culture is not a system of abstract values separate from individuals and therefore it is inseparable (from the individual). Culture is hence inseparable from its historical context which comprises what happened in the past, shared beliefs, attitudes, norms, roles, and values possessed by a given language speakers coexisting in a certain geographic region at certain time frame (Triandis, 1995). He continues to explain that the shared elements of culture are usually transferred from one generation to other generations (Triandis, 1995). Thus, language, time, and place make up the crucial elements that contribute to explain culture.

Kluchon (1962) mentioned the primary elements of culture, which comprise patterns, explicit, and implicit behaviour attained and conveyed by symbols that denote human groups' distinctive achievements, which include ideas and attached values. As such, culture systems are describable as outcome of action and conditional elements of forthcoming actions. With respect to values contained within the culture, Hofstede (1991) has mentioned two value characteristics: values employed as guiding principles in life and values usable as preference for one mode of behaviour over another. Rokeach (1973) a permanent certainty that one way of conduct or endstate of existence is the preferred one in comparison to the opposing ones has described the concept of values. On the other hand, Mead (1996) perceives value as an abstract concept that a group or a society regards as good, right and desirable.

\section{Research Framework and Hypothesis}

Based on the factors that potentially affect acceptance of users of E-commerce, the cultural factor is included in the Unified Theory of Acceptance and Use of Technology (UTAUT). This will allow the examination on the factors that have the potential to influence the acceptance of university student towards e-commerce.

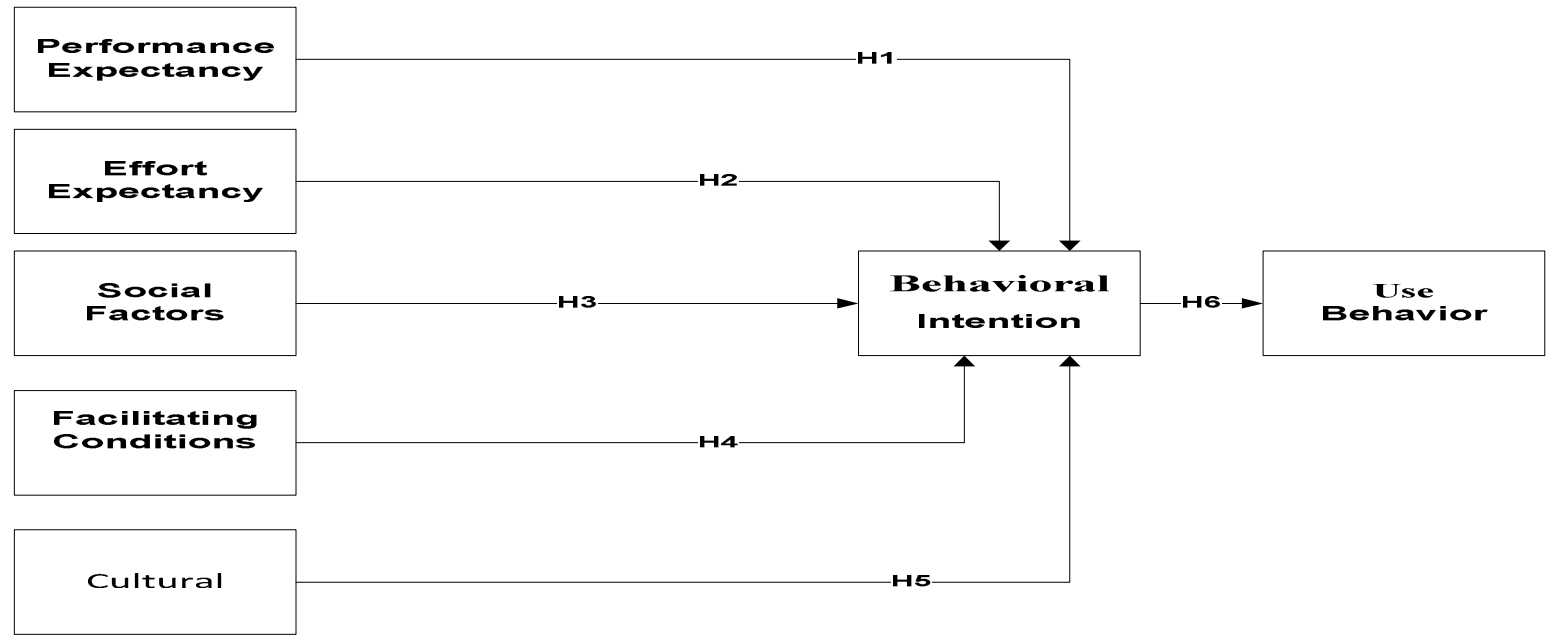

Figure 2: Research Framework

\section{Research Hypothesis}

H1: Performance Expectancy has a significant positive relationship with behavioral intention to use E-commerce.

H2: Effort Expectancy has a significant positive relationship with behavioral intention to use Ecommerce. 
H3: Social Factors have a significant positive relationship with behavioral intention to use Ecommerce.

H4: Facilitating Conditions have a significant positive relationship with behavioral intention to use E-commerce.

H5: Cultural factors have a significant positive relationship with behavioral intention to use Ecommerce.

H6: Behavioral Intention has a significant positive relationship with Use Behavior to use Ecommerce.

\section{Research Methodology}

This study selected 154 students from the Jordan universities to be participants. Data were acquired online (online questionnaires at (www.surveyshare.com). The questionnaire comprises one part and this part includes five key constructs that have association with behavioral intention to use E-commerce. This will allow the evaluation on the likelihood of level of acceptance. A number of items each represents the constructs and the 5-point scale is employed to measure the level of acceptance of user. The relationship between the six main factors and usage of E-commerce is ascertained by the regression analysis.

\section{Data Analysis and Results}

The outcomes demonstrate the significance of all constructed hypotheses according to the zero-order correlation test. Each hypothesis is supported at this level. As for the predictive model, it entails $53.1 \%$ of the variance in behavioral intention (BI). This result is directly explainable by performance expectancy, effort expectancy, social influence, facilitating conditions, and culture as well. Moreover, the model accounts to $43.1 \%$ of the variance in Use Behaviour and behavioral intention and Use Behavior directly illustrate this. Figure 3 highlights the predictive models with $\mathrm{R}^{2}$ alongside the path coefficients in the research model.

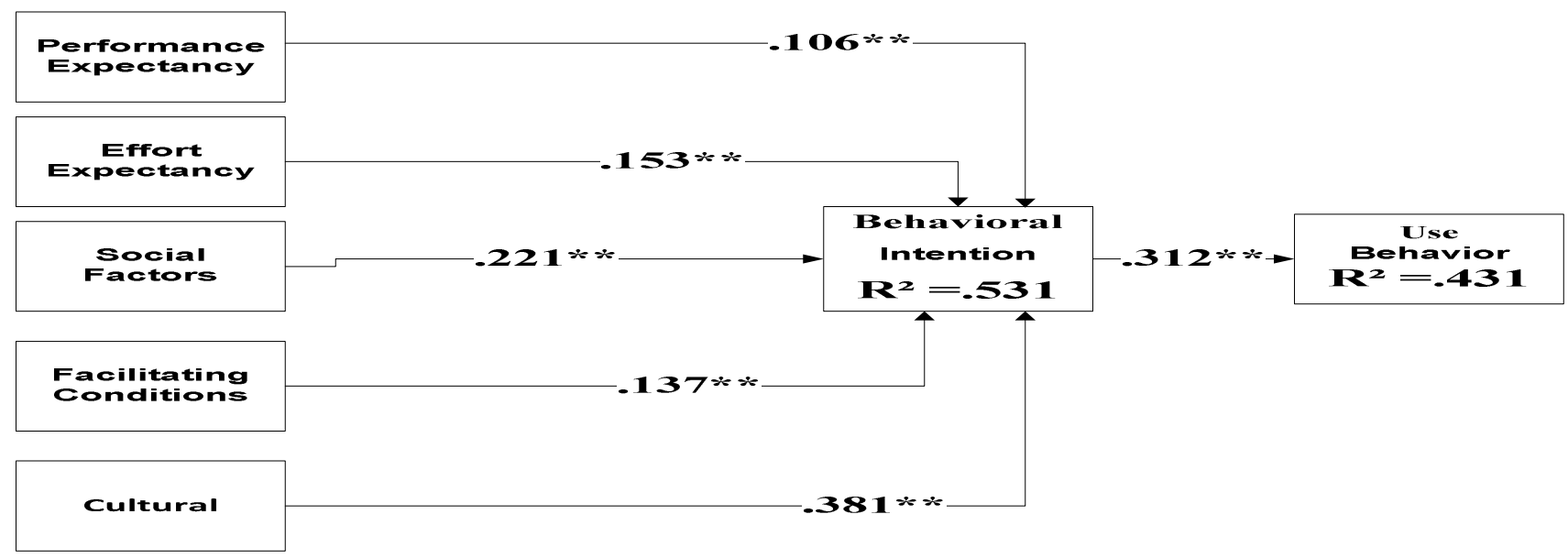

\section{Discussion and Implications}

Figure 3: Measurement Model

The level of Jordanians' willingness to employ e-commerce services is explored in this research. Pperformance expectancy, effort expectancy, social influence, and facilitating conditions and cultural ones were employed and explained. Thus, to assure that students' usage of e-commerce could be increased, these factors should be considered by the government. Data were obtained from citizens from numerous domains, making the generated results (from analyses) more representative of the population. For the context of Jordan, a model is proposed. This model contains the constructs from the Unified Theory of Acceptance and Use of Technology (UTAUT). Considering the factors of trust, perceived usefulness, perceived ease of use, attitude toward, behavioral intention, and actual 
system use, it can be said that citizen's intent to use e-commerce will increase with the belief that the internet would increase their efficiency in their interaction with the government, as they have better control, and when they gather information from the government.

The government must make effort to increase the awareness of the citizens about the service offered online. This is possible via the adoption of an awareness initiative. In addition, the government should make use of the present technology such as the social media. Switching to the use of modern medium from the conventional one can increase effectiveness as the government could provide information to the citizens in real time. It is suggested that the proposed model is used in the future researches with other constructs added. Among the possible constructs to be added are perceived ease of use and trust factor. In addition, sample in a future studyshould be obtained from other regions in Jordan.

\section{Practical implications}

The results provide useful contributions and implications to acceptance to use e commerce among students. This study indicates that e-commerce marketing has positive effect on students. Moreover, the results suggest that online customer Performance expectancy, effort expectancy, social influence, and facilitating conditions and cultural positive influence on e-commerce marketing strategy.

\section{Research limitations}

The respondents in this study were chosen randomly. However, according to (Ruiz Mafé et al., 2013; Lacka et al., 2014 ; Morris \& Probets, 2013; Nusair, 2011 and Faqih, (2011) the main issues faced in ecommerce are various such as those that are related to security, trust, Internet experience, technology acceptance, social influence, performance expectancy, effort expectancy, social influence, facilitating conditions, and culture values which means that the choice of respondents is not merely based on the age and Internet experience only but also whether the respondents have the interest in shoppingboth online and conventionally and many other variables. Consequently, in a future study, the questionnaires must be distributed to more various backgrounds of respondents in more diverse locations. In this study, most of the respondents of the questionnaires were focused in students from the Jordan universities to be participants because it has many Internet cafes. In a future study, however, a researcher needs to distribute his/her questionnaires to students, homemakers, executives, teachers, and/or business people in malls, schools, housing complexes, or many other public places.

\section{Conclusion}

The last decade has seen the growth of E-Commerce in the developed countries. This has sparked interest among the developing ones especially those located in the Middle East region. These countries know that to be able to be a player in the domain of e-Commerce is crucial. Countries in the Middle East should apply the Internet technology in e-commerce particularly. The users of the Internet in A majority of countries in the Middle East are still lagging in their diverse use in comparison to those users in the developed countries such as South East Asia, America and Europe. Actually, E-Commerce sites in Arab countries are still really scarce. The main objective of this study was to increase the intention to use of Arab users of Jordan e-commerce websites. As such, the increase for Jordan e-commerce websites is expected to change the consumer is online buying intentions. Such change will lead to the improvement of the microeconomics of Arab countries. The study provides validation to the framework model on the Arabic Websites setting and the industry of online shopping in general.

\section{Reference}

Chaffey, D. 2007. E-business and e-commerce management: strategy, implementation and practice. http://www.amazon.co.uk/E-Business-E-CommerceManagement-StrategyImplementation/dp/0273719602, [17-7-2015]. 
Kalakota, R. and Whinston, A. B. 1997. Readings in electronic commerce. Ed. Addison-Wesley Longman Publishing Co., Inc

Johnson, R., Clayton, M., Xia, G., Woo, J. H. and Song, Y. 2002. The strategic implications of e-commerce for the design and construction industry. Engineering Construction and Architectural Management 9(3): 241-248.

Nielsen Global Report, Global consumer confidence, Concerns and Spending, October 2010

Abbad, M., Abbad, R. and Saleh, M. 2011. Limitations of e-commerce in developing countries: Jordan case. Education, Business and Society: Contemporary Middle Eastern Issues 4(4): 280 291.

Hasan, L., Morris, A., \& Probets, S. (2013). E-commerce websites for developing countries-A usability evaluation framework. Online Information Review, 37(2), 231-251

Yaseen, H., Dingley, K., \& Adams, C. (2015, June). The government's role in raising awareness towards e-commerce adoption: the case of Jordan. In Proceedings of the 15th European Conference on eGovernment 2015: ECEG 2015 (p. 316). Academic Conferences Limited.

Al-Soud, A. R., \& Nakata, K. (2010, December). Evaluating e-government websites in Jordan: Accessibility, usability, transparency and responsiveness. In Progress in Informatics and Computing (PIC), 2010 IEEE International Conference on (Vol. 2, pp. 761-765). IEEE.

Pons, A., Aljifri, H. and Fourati, K. 2003. E-commerce and Arab intra-trade. Information Technology \& People 16(1): 34-48.

Fang, Y., Qureshi, I., Sun, H., McCole, P., Ramsey, E., \& Lim, K. H. (2014). Trust, satisfaction, and online repurchase intention: the moderating role of perceived effectiveness of e-commerce institutional mechanisms. MIS Quarterly, 38(2), 407-427.

Hasan, L., Morris, A., \& Probets, S. (2013). E-commerce websites for developing Countries-A usability evaluation framework. Online Information Review, 37(2), 231-251.

Venkatesh, V., Morris, M. G., Davis, G. B. and Davis, F. D. 2003. User acceptance of information technology: Toward a unified view. MIS quarterly 425-478.

Chang, L.-C. and Chuang, H. 2005. The study of subculture and consumer behavior: An example of Taiwanese University students' consumption culture. Journal of American Academy of Business 7(2): 264.

Triandis, H. C. 1995. Individualism \& collectivism. Ed. West view press.

Hostede, G. 1991. Cultures and organizations: software of the mind. New York: McGraw Hill 1997(2347.

Rokeach, M. 1973. The nature of human values. Ed. Free press New York. Mead, R. 1996. International Management: Cross Cultural Dimensions. Long Range Planning 3(29): 424-425. 